\title{
Awareness of Bell's Palsy Among Dental Students
}

\author{
Sivesh Sangar, Kiran Kumar and Dhanraj Ganapathy \\ ${ }^{1}$ Saveetha Dental College and Hospitals Saveetha Institute of Medical \\ and Technical Sciences Saveetha University Chennai-77, India \\ ${ }^{2}$ Reader, Department of Oral Medicine and Radiology, Saveetha Dental \\ College and Hospitals, Saveetha Institute of Medical and Technical Science, \\ Saveetha University, Chennai-77 \\ ${ }^{3}$ Professor and Head, Department of Prosthodontics, Saveetha Dental College and Hospitals, \\ Saveetha Institute of Medical and Technical Science, Saveetha University, Chennai-77, India
}

\section{ABSTRACT}

Awareness of Bell's palsy is important in dentistry as it deals with the facial nerves on the facial regions. Being a dentist, we should need to have knowledge about the signs of Bell's palsy which is caused by inflammation developing around the nerve of the facial and as it passes through the skull from the brain the inflammation compresses the nerve as it passes through the skull. The aim of our study is to assess the awareness and knowledge on Bell's palsy among dental students. This study was conducted by assessing responses to seven questions among dental students through a survey planet. A detailed questionnaire is related to awareness and knowledge of participants about Bell's palsy. The results were recorded and analyzed. Nearly $95 \%$ of the students claimed that they have an excellent knowledge about Bell's palsy and the remaining $5 \%$ not aware of the term Bell's palsy. About 93\% answered that they are aware of the causes of Bell's Palsy and $7 \%$ of the students answered that they have no clue about the causes of Bell's Palsy. About 63\% do not have an idea about the chances of recurrence for a Bell's palsy patient and the rest $27 \%$ of the students were confident that they were well versed with the precautions that should be followed while handling a Bell's palsy patient. As a conclusion, awareness regarding Bell's palsy has to be improved among dental students and they should be able to plan a proper treatment plan in managing Bell's palsy in future.

\section{KEY WORDS: AWARENESS, BELL'S PALSY, FACIAL MUSCLES, MANAGEMENT.}

\section{INTRODUCTION}

Bell's palsy is a condition that suddenly affects movement of the facial muscles on one side of the face. (Meslet et al., 2019). Bell's palsy is named after the discovery by Scottish anatomist Charles Bell's Palsy

\section{ARTICLE INFORMATION}

*Corresponding Author: dhanraj@saveetha.com

Received 15th June 2020 Accepted after revision 12th August 2020 Print ISSN: 0974-6455 Online ISSN: 2321-4007 CODEN: BBRCBA

Thomson Reuters ISI Web of Science Clarivate Analytics USA and Crossref Indexed Journal

\section{Clarivate}

NAAS Journal Score 2020 (4.31) SJIF: 2020 (7.728)

A Society of Science and Nature Publication,

Bhopal India 2020. All rights reserved.

Online Contents Available at: http//www.bbrc.in/

Doi: http://dx.doi.org/10.21786/bbrc/13.7/4
(Harini and Prabu, 2019) It affects men and women equally. It may occur in between ages of 10 to 60. People who have diabetes and pregnant women are more likely to develop Bell's palsy. It is reported that about 1 in 70 people have Bell's palsy in their life and in 10\% of cases family history may also be the cause of Bell's Palsy. (Salinas et al., 2010)

Bell's palsy develops around the nerve of facial and as it passes through the skull from the brain the inflammation compresses the nerve as it passes through the skull and the nerve stops working until inflammation goes away. Cranial nerves and muscles will stop working. The virus that causes herpes simplex, herpes zoster, Respiratory

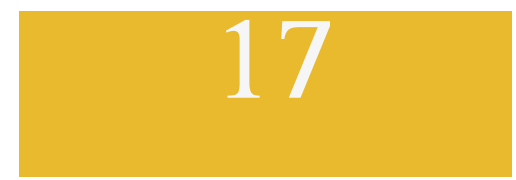


illnesses (adenovirus) German measles (rubella), Mumps (mumps virus), Flu (influenza B) has been linked to Bell's palsy.(Sullivan et al., 2007).

Bell's palsy influences ear infection, cold, eye infection. The symptoms appear rapidly and might notice them on waking, eating or drinking. Bell's palsy is marked by one side droopy appearance and the inability to open/ close eyes on the affected side. In some cases it may affect both sides of the face(Lancaster and Crow, 2006) The drugs of choice for Bell's palsy corticosteroid used which reduce inflammation, antiviral medication if virus is the cause and pain medication ibuprofen or acetaminophen for mild pain are used. Vitamin B-12 and B-6 are B-complex vitamins that are important for preventing Bell's palsy. Physical therapies can and exercise facial muscles helpful for preventing this from occurring and plastic surgery may be needed to correct lasting facial nerve problems. Good nutrition and rest helpful for body as it heals.(Miles, 1992) In some cases Bell's palsy is a "one-off" and about 1 in 10 people have a Bell's palsy can have a further episode in the future happen often several years afterwards and no ways to prevent the development of this disease.

Previously our department has published extensive research on various aspects of prosthetic dentistry ('Evaluation of Corrosive Behavior of Four Nickelchromium Alloys in Artificial Saliva by Cyclic Polarization Test:An in vitro Study', 2017; Ganapathy, Kannan and Venugopalan, 2017; Jain, 2017a, 2017b; Ranganathan, Ganapathy and Jain, 2017; Ariga et al., 2018; Gupta, Ariga and Deogade, 2018; Anbu et al., 2019; Ashok and Ganapathy, 2019; Duraisamy et al., 2019; Varghese, Ramesh and Veeraiyan, 2019), this vast research experience has inspired us to research about the awareness of bell's palsy among dental students.

\section{MATERIAL AND METHODS}

Participants and study design: A questionnaire-based survey study that was conducted engaged a selfadministered questionnaire at the Saveetha Dental College and Hospital. The participants were informed in priory about the objective of the study. The participants were entirely non-mandatory and their identities were kept anonymous.

Data Collection Methods: A study was conducted to assess the responses to 7 selected questions regarding Bell's palsy among dental students through survey planet among 100 dental students. The questionnaire is about the awareness and knowledge toward Bell's palsy. They were asked about the details of causes, signs and management of Bell's palsy and exclusion of study is incomplete responses. The results were recorded and analyzed.

\section{RESULTS AND DISCUSSION}

Awareness of participants related to Bell's palsy was evaluated to assess the first set of questions; only $95 \%$ of the students knew about it and the rest 5\% were not aware of the term Bell's palsy. About 93\% participants were aware of causes of Bell's palsy and the remaining 7\% participants have no clue about the causes of Bell's palsy. About 89\% of the participants know about the signs and symptoms of Bell's palsy and 11\% were not aware of signs and symptoms for Bell's palsy. About 82\% answered that they were aware of treatment of Bell's palsy and rest Nearly 63\% of the participants about the chances of recurrence for a Bell's palsy patient. Only 27 $\%$ of the students were confident that they were well versed with the precautions that should be followed while handling a Bell's palsy patient and the rest of $46 \%$ were not aware of the precautionary methods that should be taken while treating a Bell's palsy patient for dental treatment.

Figure 1: Awareness of Bell's Palsy. The pie chart shows the awareness towards the term of bell's palsy among 100 students. 95 students answered Yes(blue) while 5 students answered No (Red).

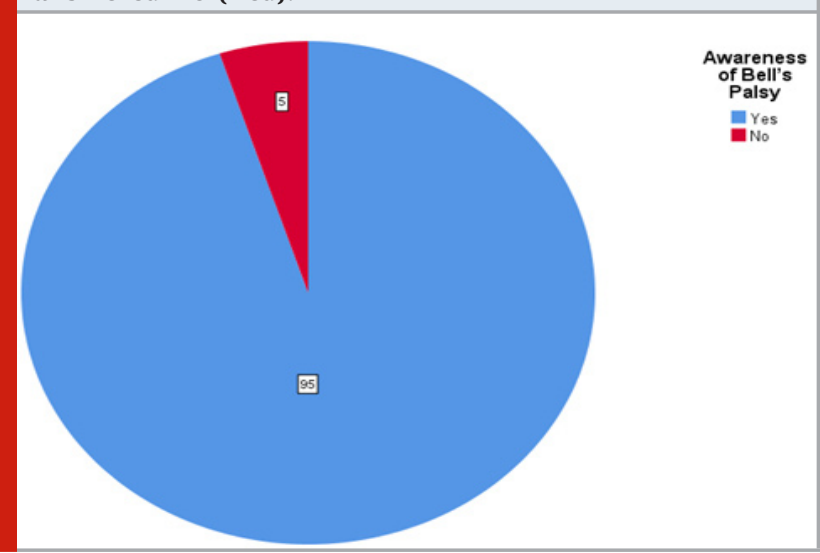

Figure 2: Causes of Bell's Palsy. The pie chart shows the distribution of students towards the awareness of causes of bell's palsy among 100 students. 93 students answered Yes(blue) while 7 students answered No (Red)

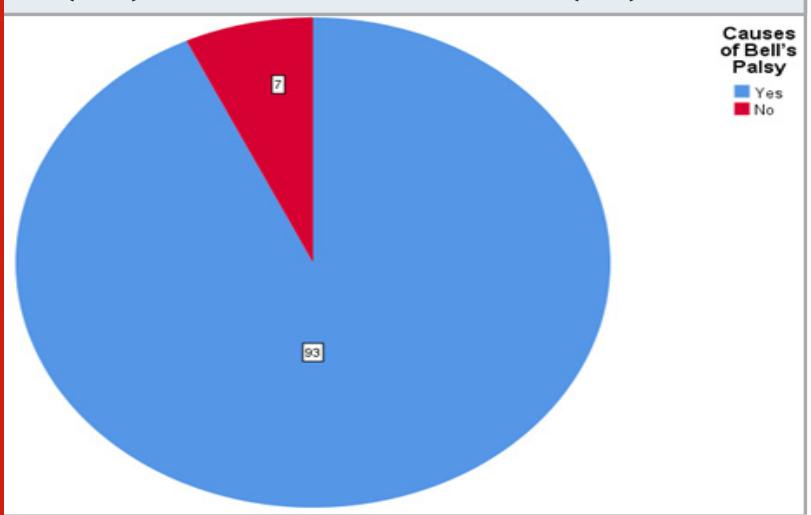

The present study is to assess knowledge and awareness of Bell's palsy among dental students in Saveetha Institute of Medical and Technical Sciences. According to this study the dental undergraduates and intern's awareness of bell's palsy was satisfactory, the participants generally 
have reasonable information about bell's palsy so they are aware enough about the disease. This present study examines the knowledge and attitude among the dentists on Bell's palsy, to our knowledge there have almost no reported studies on knowledge and attitude of Bell's palsy among dental students. A study was conducted in Karachi, Pakistan on the knowledge and awareness of Bell's palsy among students of pharmacy, science and arts faculties. It is observed that out of 120 students, only 61.67\% students knew about Bell's palsy. Knowledge and awareness of Bell's palsy among students was inadequate.(Naveed and Tasleem, 2014)

Figure 3: Signs and symptoms of Bell's Palsy. The pie chart shows the distribution of students towards the awareness of the signs and symptoms of bell's palsy among 100 students. 89 students answered Yes(blue) while 11 students answered No (Red)

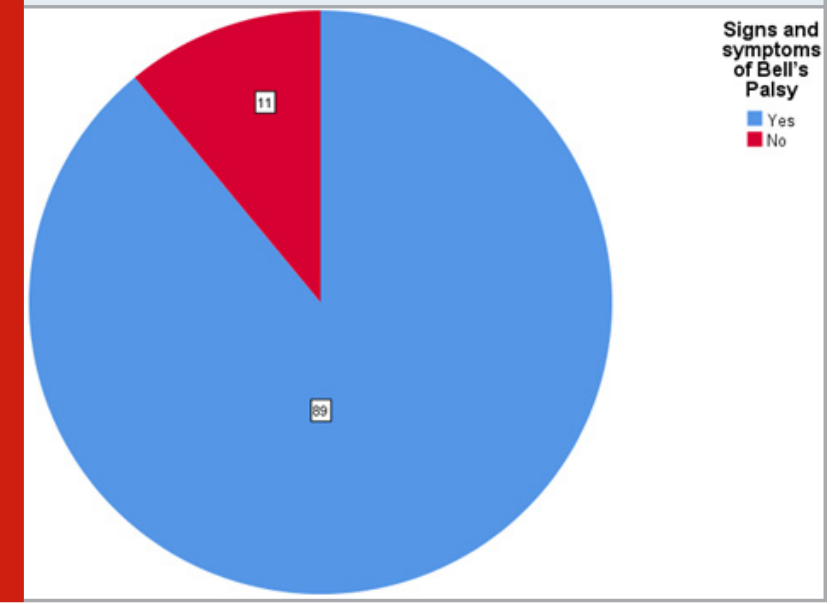

Figure 4: Treatments of Bell's Palsy. The pie chart shows the distribution of students towards the awareness of treatments for bell's palsy among 100 students. 82 students answered Yes(blue) while 18 students answered No (Red)

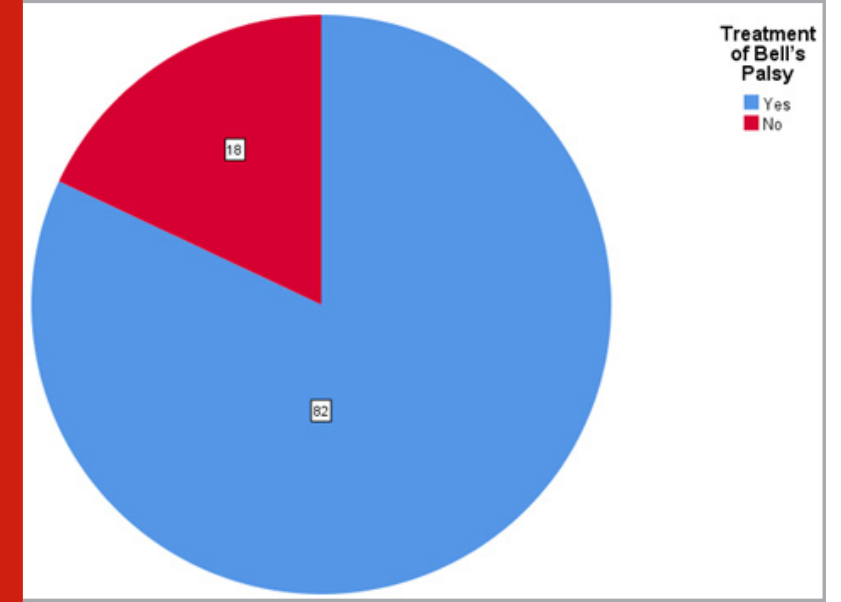

Costa et al. 2000 reported that the level of knowledge about Bell's palsy risk factors and its treatment was poor with the participants generally have limited information about bell's palsy and the community awareness of bell's palsy is low they are not aware enough. (Apostolides and Carr, 2000). The main cause of the disease is not yet clear, it is linked to exposure to a viral infection such as the varicella-zoster virus and Epstein-Barr viruses, both of herpes family (Brandenburg and Annegers, 1993), in this study 38\% have awareness about the etiology. Another study was conducted in Riyadh, Kingdom of Saudi Arabia (KSA) in 2016 on the awareness and knowledge of neurological complications while administering local anesthesia among the dental professionals which included students and practitioners.(AlYahya, Al-Qernas and Al-Shaheen, 2018); (Hasan, Ganapathy and Jain, 2018)

Figure 5: Recurrence chance of Bell's Palsy. The pie chart shows the distribution of students towards the awareness of the chance of recurrence of bell's palsy among 100 students. 37 students answered Yes(blue) while 63 students answered No (Red)

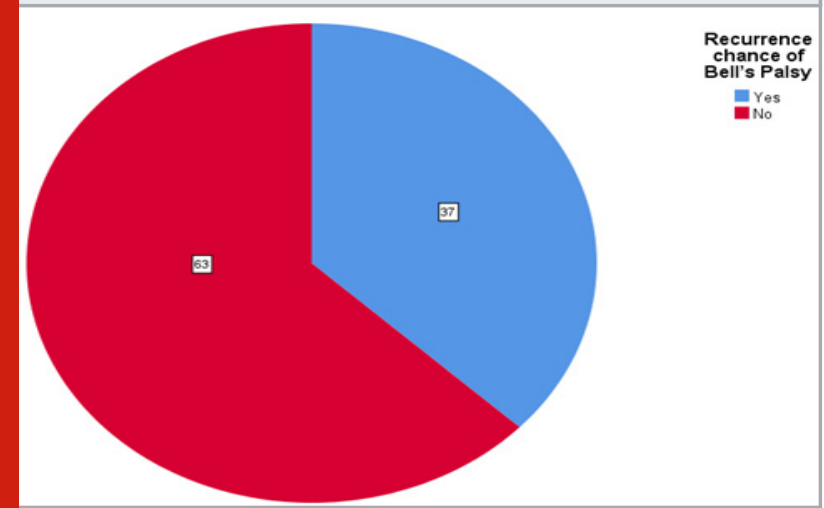

Figure 6: Precautions for patients with Bell's Palsy. The pie chart shows the distribution of students towards the awareness of precautions of bell's palsy among 100 students. 27 students answered Yes(blue) while 73 students answered No (Red)

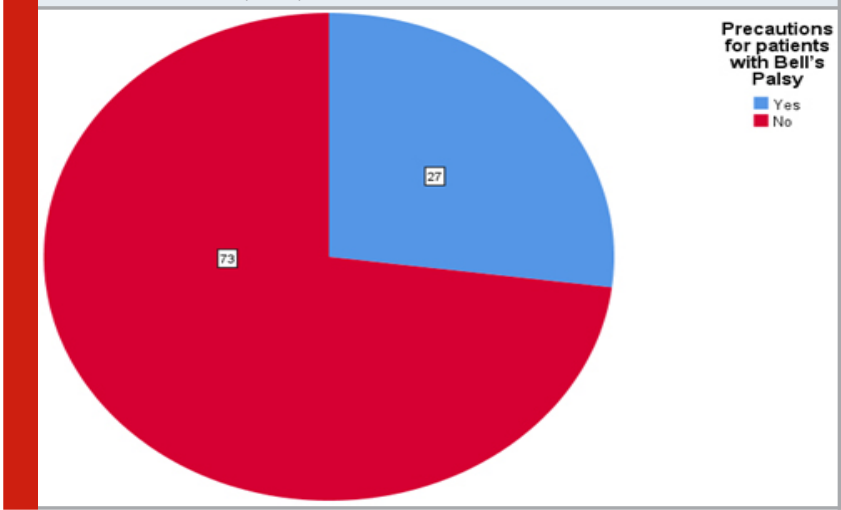

In a case report study by Chevalier et al., it was found that after two hours of administration of inferior alveolar nerve block the patient felt the complete onset of paralysis on the left-side of the facial muscles which the neurologists diagnosed as Bell's palsy after looking into other medical history of the patient (Ilea et al., 2014; Aravinth and Ganapathy, 2019). It is important that a dentist has adequate knowledge on 
Bell's Palsy as he may be treating a patient with existing facial palsy, or may be the first medical professional to observe it in a patient, or may be the one to induce iatrogenic reactions causing Bell's palsy to the patient during dental treatment (Jd, 2007; Prakash, Ganapathy and Mallikarjuna, 2019). In a study on Bell palsy and its clinical significance, it was concluded that knowledge of the anatomy and clinical significance of Bell's palsy may help to make accurate diagnosis and give proper treatment.

Figure 7: Awareness on the precautionary methods for patients with Bell's Palsy. The pie chart shows the distribution of students towards the awareness of precautionary methods to be followed while dealing with bell's palsy among 100 students. 54 students answered Yes(blue) while 46 students answered No (Red)

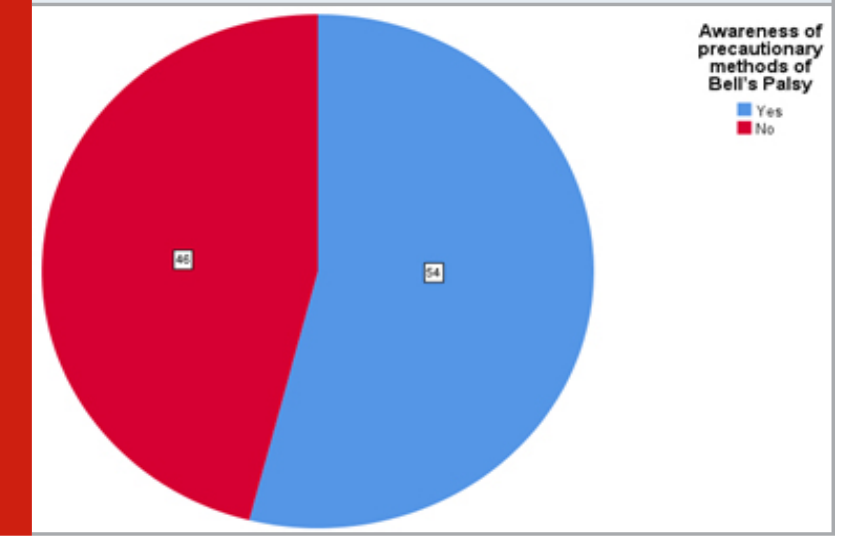

CONCLUSION

Within the limits of our study, it is concluded that the knowledge of Bell's palsy in students is not enough to dial uncertain mishap pining of the disease $\mathcal{C}$ the must aware to the disease to treat other more better otherwise they will not cover fully to this disease. Unfortunately, dental consideration of Bell's palsy, the participant not aware to manage patients with Bell's palsy if it is happened immediately after dental procedure. Knowledge of the anatomy and clinical significance of Bell's palsy may help to make accurate diagnosis and provide appropriate treatment. We recommend that dental students and dentists should be exposed to any medical conditions that could happen because of iatrogenic reasons.

\section{ACKNOWLEDGEMENTS}

We the authors of the manuscript, would like to thank and acknowledge Saveetha Dental College for providing us access to use the retrospective data for the study.

\section{Authors Contribution}

Sivesh Sangar contributed to the study design, data collection, data analysis, preparation of the manuscript.
Dhanraj Ganapathy contributed to the study design, data collection, and preparation of the manuscript.

Kiran Kumar contributed to the study design, preparation of the manuscript and proofreading.

Conflict of Interest: This research project is self funded. There is no conflict of interest.

\section{REFERENCES}

AlYahya, K., Al-Qernas, A. and Al-Shaheen, A. (2018) 'Awareness about Bell's palsy common risk factors among males and females, Alhasa region of Saudi Arabia, a cross-sectional study', Egyptian Journal of Hospital Medicine. Pan Arab League of Continuous Medical Education, 31(6313), pp. 1-7.

Anbu, R. T. et al. (2019) 'Comparison of the Efficacy of Three Different Bone Regeneration Materials: An Animal Study', European journal of dentistry, 13(1), pp. 22-28.

Apostolides, C. and Carr, M. M. (2000) 'Assessment and management of idiopathic facial (Bell's) palsy: comparison of Nova Scotia family physicians and otolaryngologists', The Journal of otolaryngology, 29(1), pp. 17-22.

Aravinth, H. and Ganapathy, D. (2019) 'Knowledge about post-extraction complications among dental students', Drug Invention Today, 11(2). Available at: https://bit. ly/32euLZV.

Ariga, P. et al. (2018) 'Determination of Correlation of Width of Maxillary Anterior Teeth using Extraoral and Intraoral Factors in Indian Population: A Systematic Review', World Journal of Dentistry, 9(1), pp. 68-75.

Ashok, V. and Ganapathy, D. (2019) 'A geometrical method to classify face forms', Journal of oral biology and craniofacial research, 9(3), pp. 232-235.

Brandenburg, N. A. and Annegers, J. F. (1993) 'Incidence and Risk Factors for Bell's Palsy in Laredo, Texas: 1974-1982', Neuroepidemiology, pp. 313-325. doi: $10.1159 / 000110333$.

Duraisamy, R. et al. (2019) 'Compatibility of Nonoriginal Abutments With Implants: Evaluation of Microgap at the Implant-Abutment Interface, With Original and Nonoriginal Abutments', Implant dentistry, 28(3), pp. 289-295.

'Evaluation of Corrosive Behavior of Four Nickelchromium Alloys in Artificial Saliva by Cyclic Polarization Test:An in vitro Study' (2017) World Journal of Dentistry, 8(6), pp. 477-482.

Ganapathy, D. M., Kannan, A. and Venugopalan, S. (2017) 'Effect of Coated Surfaces influencing Screw Loosening in Implants: A Systematic Review and Meta-analysis', World Journal of Dentistry, 8(6), pp. 496-502.

Gupta, P., Ariga, P. and Deogade, S. C. (2018) 'Effect of Monopoly-coating Agent on the Surface Roughness of a Tissue Conditioner Subjected to Cleansing and Disinfection: A Contact Profilometric Study', 
Contemporary clinical dentistry, 9(Suppl 1), pp. S122S126.

Harini, K. and Prabu, D. (2019) 'Awareness and Knowledge of Neurological Complications and its Management while administering Local Anaesthesia among The Dental Students', Research Journal of Pharmacy and Technology, p. 483. doi: 10.5958/0974360x.2019.00085.4.

Hasan, S. A., Ganapathy, D. and Jain, A. (2018) 'Knowledge and awareness among undergraduate students on human immunodeficiency virus transmission', Drug Invention Today, 10, pp. 3285-3288.

Ilea, A. et al. (2014) 'Management of patients with facial paralysis in the dental office: A brief review of the literature and case report', Quintessence international , 45(1), pp. 75-86.

Jain, A. R. (2017a) 'Clinical and Functional Outcomes of Implant Prostheses in Fibula Free Flaps', World Journal of Dentistry, 8(3), pp. 171-176.

Jain, A. R. (2017b) 'Prevalence of Partial Edentulousness and Treatment needs in Rural Population of South India', World Journal of Dentistry, 8(3), pp. 213-217. Jd, T. (2007) 'khatkhate n. Bell's palsy: diagnosis and management', American family physician.

Lancaster, D. G. and Crow, W. T. (2006) 'Osteopathic manipulative treatment of a 26-year-old woman with Bell's palsy', The Journal of the American Osteopathic Association, 106(5), pp. 285-289.

Meslet, A. A. et al. (2019) 'Knowledge and awareness of sickle cell anemia among dental students in Riyadh
Elm University', Journal of Dental Health, Oral Disorders \&t Therapy, pp. 218-224. doi: 10.15406/ jdhodt.2019.10.00488.

Miles, P. G. (1992) 'Facial palsy in the dental surgery. Case report and review', Australian dental journal, 37(4), pp. 262-265.

Naveed, S. and Tasleem, H. N. (2014) 'Bell's Palsy “Laqwa”: Survey Based Study', OALib, pp. 1-5. doi: 10.4236/oalib.1100487.

Prakash, M. S., Ganapathy, D. M. and Mallikarjuna, A. V. (2019) 'Knowledge awareness practice survey on awareness of concentrated growth factor among dentists', Drug Invention Today, 11(3). Available at: https://bit.ly/2Zoroh9

Ranganathan, H., Ganapathy, D. M. and Jain, A. R. (2017) 'Cervical and Incisal Marginal Discrepancy in Ceramic Laminate Veneering Materials: A SEM Analysis', Contemporary clinical dentistry, 8(2), pp. 272-278.

Salinas, R. A. et al. (2010) 'Corticosteroids for Bell's palsy (idiopathic facial paralysis)', Cochrane database of systematic reviews , (3), p. CD001942.

Sullivan, F. M. et al. (2007) 'Early treatment with prednisolone or acyclovir in Bell's palsy', The New England journal of medicine, 357(16), pp. 1598-1607. Varghese, S. S., Ramesh, A. and Veeraiyan, D. N. (2019) 'Blended Module-Based Teaching in Biostatistics and Research Methodology: A Retrospective Study with Postgraduate Dental Students', Journal of dental education, 83(4), pp. 445-450. 